\title{
Tear protein analysis in presumed congenital alacrima
}

This article was published in the following Dove Medical Press journal: Clinical Ophthalmology

\author{
Shigeharu Yaginuma' \\ Yoko Akune ${ }^{2}$ \\ Chika Shigeyasu', \\ Yoji Takano ${ }^{3}$ \\ Masakazu Yamada \\ 'Department of Ophthalmology, \\ Kyorin University School of Medicine, \\ Tokyo I8I-86II, Japan; '2Division for \\ Vision Research, National Institute \\ of Sensory Organs, National Hospital \\ Organization Tokyo Medical Center, \\ Tokyo 152-8902, Japan; ${ }^{3}$ Department \\ of Ophthalmology, Kawasaki Municipal \\ Ida Hospital, Kawasaki 2I I-0035, \\ Japan
}

Objectives: It is often hard to reach a definitive diagnosis of congenital alacrima because of the difficultly in proving the lack of lacrimal tissue. We report here the distinct tear protein profile in presumed congenital alacrima.

Patients and methods: A 13-year-old girl with presumed congenital alacrima and 15 healthy volunteers aged 23-35 years were included in this study. Tears were collected using Schirmer strips, and tear protein analyses were performed. Tear samples were collected from the patient with alacrima before and after surgical punctal occlusion of both the upper and lower puncta, and tear protein extract was fractionated using HPLC. Lactoferrin and albumin concentrations in the tears were separately determined using ELISA.

Results: The chromatogram in the patient greatly differed from that in normal subjects with low concentrations of secretory IgA, lipocalin-1, and lysozyme. ELISA results indicated that the tear fluid in the patient contained a high concentration of albumin but a minimal concentration of lactoferrin. Punctal occlusion improved the ocular surface findings, but major lacrimal protein concentrations remained low and tear albumin concentrations further increased.

Conclusion: The tear protein profile of a patient with presumed congenital alacrima greatly differed from that of normal subjects. Tear protein analysis may be useful in making a diagnosis of congenital alacrima and in assessing the efficacy and mechanism of punctal occlusion.

Keywords: alacrima, albumin, dry eye, lactoferrin, tears

\section{Introduction}

Congenital alacrima is a rare disease presenting as severe keratoconjunctivitis sicca that is present since infancy. ${ }^{1-3}$ Autosomal dominant and recessive traits have both been reported in congenital alacrima, and it may also present as a part of the triple A syndrome, an autosomal recessive disease characterized by esophageal achalasia, alacrima, and adrenal insufficiency. ${ }^{4,5}$ Systemic findings and family history are not present in all cases, and it is often hard to reach a definitive diagnosis because of the difficultly in proving the lack of lacrimal tissue. We hypothesized that tear protein analysis could provide a new information to make a diagnosis of alacrima, because the protein composition of tear fluid is known to be unique and differs from that of the serum or extracellular fluid. ${ }^{6,7}$

The total protein concentration in tears is approximately one-tenth of that of the serum. ${ }^{6,7}$ Lactoferrin, lipocalin-1, lysozyme, and secretory IgA are the major tear proteins, whereas albumin, a representative serum protein, is present in very low concentrations in normal tears. ${ }^{8}$ However, compositional changes in tear fluid occur in pathological conditions, eg, lysozyme, lactoferrin, lipocalin-1 concentrations, are significantly decreased in the tears of patients with dry eye disease, whereas albumin concentrations are significantly increased..$^{9,10}$ Thus, tear fluid is recognized as a mixture
Correspondence: Masakazu Yamada Department of Ophthalmology, Kyorin University School of Medicine, 6-20-2 Shinkawa, Mitaka, Tokyo I8I-86II, Japan Tel +8 I 4224755 I I

Fax +8I 422440674

Email yamada@eye-center.org 
of secretions originating from the main lacrimal glands, accessory lacrimal glands, meibomian glands, and ocular surface epithelium. ${ }^{1-13}$ Conjunctival water flow accounts for $10 \%$ of the total water supply under normal conditions in the current model of tear dynamics. In dry eye, increased tear osmolarity drives the osmotic water flow by up to $50 \%$ of the lacrimal supply rate, significantly contributing to tear fluid. ${ }^{14,15}$ We speculated that simultaneous albumin and lactoferrin measurements could provide a new perspective for determining the source of tear fluid.

We studied the patient's tear protein profile and observed some interesting findings. In addition, we discussed the efficacy and mechanism of punctal occlusion in this patient.

\section{Patients and methods Subjects}

Participants of the study included a 13-year-old girl with presumed congenital alacrima and 15 healthy volunteers (six males and nine females; aged 23-35 years [27.9 \pm 3.7 years, mean $\pm \mathrm{SD}]$ ) serving as normal controls who had no history of eye disease, except for refractive errors. Inclusion criteria for normal controls in the study were based on the diagnostic criteria defined by the Japan Dry Eye Society. ${ }^{16,17}$ All controls had Schirmer values $>5 \mathrm{~mm}$, tear film break-up times longer than 5 seconds, and no apparent fluorescein staining of the cornea and conjunctiva. Schirmer values of normal controls were $22.3 \pm 10.3 \mathrm{~mm}$ (range, 6-35 mm), and tear film break-up time values were $8.1 \pm 2.2$ seconds (range, 6-15 seconds).

The patient with presumed congenital alacrima suffered from symptoms of photophobia and foreign body sensation. Upon visiting our hospital at 6 years of age, she exhibited severe keratoconjunctivitis sicca and decreased lacrimation. She had no remarkable past illnesses or systemic findings and no physical or mental developmental deficiencies. Her parents and a younger sister did not have any sign or symptom of dry eye. No abnormalities were found in their eyes. Her blood test results were negative for SS-A and SS-B antibodies. The lacrimal gland was not apparent bilaterally on MRI examination, and the lack of gland tissue on lacrimal gland biopsy suggested a diagnosis of congenital alacrima.

Treatment consisted of artificial tears and hyaluronic acid eye drops, but this did not reduce the patient's symptoms. Surgical punctal occlusion was performed at 13 years of age. Both eyes demonstrated low tear menisci and severe keratoconjunctivitis with filaments bedore punctal occlusion surgery. Schirmer test values were $0 \mathrm{~mm}$ in both eyes. Only $2 \mathrm{~mm}$ (right eye) and $4 \mathrm{~mm}$ (left eye) of the tip of
Schirmer strips in contact with the lower fornix were moist. The Schirmer strips were then used for tear protein analysis. Both eyes demonstrated improvements in ocular findings with higher tear menisci after surgery. Schirmer test values were increased to $1 \mathrm{~mm}$ in the right eye and $3 \mathrm{~mm}$ in the left eye. The patient continues to use artificial tears and hyaluronic acid eye drops, and her subjective symptoms have been maintained at relatively mild levels.

Guidelines developed by the World Medical Association Declaration of Helsinki were followed. The patient and the controls received a full explanation of the procedures and provided written informed consent prior to participation in the study. The protocol was approved by the institutional review board of Kyorin University School of Medicine (project \# 679).

\section{Tear samples}

Tears were collected by inserting a Schirmer test strip (Alcon, Inc., Fort Worth, TX, USA) in the lower fornix with the subject's eyes closed. Topical anesthesia was not used to eliminate the possibility of compositional changes in tears caused by anesthetic eyedrops. ${ }^{6,7}$ The strips were removed after 5 minutes, immediately placed in a $1.5-\mathrm{mL}$ centrifuge tube (Eppendorf, Hamburg, Germany) and stored at $-80^{\circ} \mathrm{C}$ until it was used for assay.

\section{Tear protein analysis}

To elute the tear proteins, the Schirmer strip was soaked in $200 \mu \mathrm{L}$ PBS for 30 minutes. ${ }^{18,19}$ The Bradford method was used to determine total tear proteins, with BSA (SigmaAldrich Co., Tokyo, Japan) as a standard. Approximately $2 \mu \mathrm{L}$ of each tear protein extract was mixed with $300 \mu \mathrm{L}$ of advanced protein assay reagent (Cytoskeleton Inc., Denver, CO, USA). Total tear protein concentration of each sample was determined using a plate reader (Benchmark Plus, Bio-Rad Laboratories, Inc., Hercules, CA, USA) set at $590 \mathrm{~nm}$.

Approximately $3 \mu \mathrm{L}$ of each tear protein extract was fractionated using HPLC under the conditions used for identifying sIgA, lactoferrin, lipocalin-1, and lysozyme as described previously. ${ }^{18,19}$ Elution was performed with a 7.8 mm I.D.×300 mm TSK G3000SWXL column (Tosoh Inc., Tokyo, Japan), with a mobile phase of $0.5 \mathrm{M}$ sodium chloride and $0.1 \mathrm{M}$ sodium phosphate ( $\mathrm{pH}$ 5.0). The flow rate was $0.7 \mathrm{~mL} / \mathrm{min}$, and peaks were detected at $230 \mathrm{~nm}$.

Lactoferrin and albumin tear concentrations were separately determined using ELISA, as the peaks for lactoferrin and albumin overlap when HPLC is performed on tear 
samples as described above. Commercial ELISA kits for lactoferrin and albumin (Bethyl Laboratories, Montgomery, TX, USA) were used according to the manufacturer's instructions. Tear extract samples were diluted to concentrations of $1 / 10$ or $1 / 100$, and absorbance was measured at $450 \mathrm{~nm}$ using a plate reader (Benchmark Plus, Bio-Rad Laboratories, Inc.). The final results were expressed as $\mathrm{mg} / \mathrm{mL}$.

\section{Results}

Figure 1 shows the chromatogram of tear proteins in the patient and controls. Under chromatographic conditions for HPLC, proteins with larger molecular weights have shorter retention times and those with smaller molecular weights have longer retention times. In controls, proteins that are relatively specific to tears such as sIgA, lactoferrin, lipocalin-1, and lysozyme formed tall peaks. The chromatogram of the patient distinctly differed from that of the controls. On this scale, the peaks for sIgA, lipocalin-1, and lysozyme were minimal and almost undetectable. The peak indicating lactoferrin was tall but as it overlapped with that of albumin, it was difficult to separate them under chromatographic conditions. The chromatogram pattern for the patient did not change even after punctal occlusion.

Table 1 shows lactoferrin and albumin concentrations measured using ELISA with total protein concentration, which was greater in the patient than in the controls. Lactoferrin concentration was minimal in the patient, but albumin concentrations were high, suggesting that the lactoferrin/ albumin peak observed on HPLC in the patient mainly consisted of albumin. After punctual occlusion, lactoferrin concentrations remained unchanged in the patient; however, albumin concentrations increased to approximately twice the preoperative value.

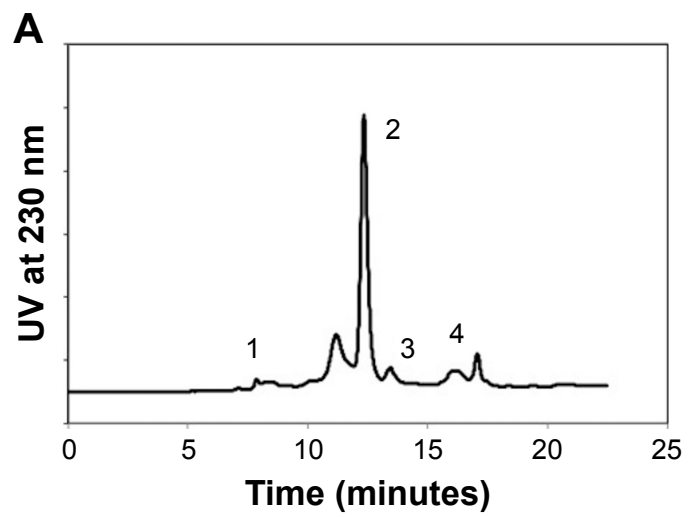

\section{Discussion}

The protein composition of tear fluids is known to be different from that of the serum and extracellular fluids. ${ }^{6-13}$ Lactoferrin, lipocalin-1, lysozyme, and sIgA are the main components of tears and are found in high concentrations in normal tears but in low concentrations in the serum. The chromatogram of the patient greatly differed from that of controls with low concentrations of SIgA, lipocalin-1, and lysozyme. The peak for lactoferrin was high, but as this peak includes both lactoferrin and albumin, lactoferrin and albumin concentrations were separately measured using ELISA, which indicated that the tear fluid in the patient contained high albumin concentrations but minimal lactoferrin concentrations. Punctal occlusion resulted in increased tear volume but minimal lactoferrin concentrations. The findings in our case are different from the report of Tong and associates who investigated the effects of punctal occlusion on global tear protein levels in patients with dry eye. ${ }^{20}$ They reported that patients with lower Schirmer scores had a reduction in the inflammatory proteins and rise in lacrimal proteins such as lysozyme and lactoferrin after punctal occlusion. Extreme low lactoferrin concentrations in our patient both before and after punctual occlusion may support the diagnosis of congenital alacrima.

The HPLC and ELISA results indicated that the concentrations of the four major tear proteins were low in the patient. Lactoferrin, lipocalin-1, and lysozyme are products of acinar tissues in the lacrimal glands. $\operatorname{sg} \mathrm{A}$ is produced by a combination of dimeric IgA from plasma cells and a secretory component synthesized in the ductal cells of the lacrimal glands. These proteins are relatively specific to tear fluid, although the sources are different. ${ }^{6,7}$ Changes in tear protein composition and concentrations have been reported under various conditions including during sleep and when

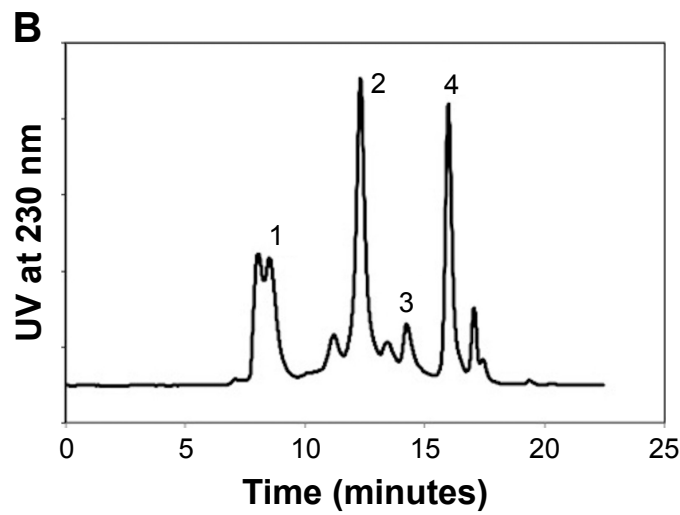

Figure I Typical HPLC of tear proteins.

Notes: Tear components normally include slgA (I), lactoferrin and albumin (2), lipocalin-I (3), and lysozyme (4). The HPLC chromatogram of the patient (A) greatly differed from that of the controls (B).

Abbreviation: UV, ultraviolet. 
Table I Lactoferrin and albumin tear concentrations

\begin{tabular}{|l|l|l|l|l|}
\hline Punctal occlusion & Eye & $\begin{array}{l}\text { Albumin } \\
(\mathbf{m g} / \mathbf{m L})\end{array}$ & $\begin{array}{l}\text { Lactoferrin } \\
(\mathbf{m g} / \mathbf{m L})\end{array}$ & $\begin{array}{l}\text { Total protein } \\
(\mathbf{m g} / \mathbf{m L})\end{array}$ \\
\hline \multirow{2}{*}{ Patient preoperative } & $\mathrm{R}$ & 0.76 & 0.025 & 8.9 \\
\cline { 2 - 5 } & $\mathrm{L}$ & 1.13 & 0.011 & 9.3 \\
\hline \multirow{2}{*}{ postoperative } & $\mathrm{R}$ & 1.83 & 0.011 & 13.9 \\
\cline { 2 - 5 } & $\mathrm{L}$ & 2.99 & 0.008 & 15.8 \\
\hline \multirow{2}{*}{ Controls ( $\mathrm{n}=15)$} & $\mathrm{R}$ & $0.32 \pm 0.27$ & $1.61 \pm 0.47$ & $7.29 \pm 1.51$ \\
\cline { 2 - 5 } & $\mathrm{L}$ & $0.36 \pm 0.30$ & $1.58 \pm 0.42$ & $7.62 \pm 1.96$ \\
\hline
\end{tabular}

Notes: Lactoferrin and albumin tear concentrations measured using ELISA with total protein assay revealed minimal lactoferrin concentration in the patient but high albumin concentrations. Lactoferrin concentrations after punctual occlusion remained unchanged in the patient, but albumin concentrations increased to approximately twice the preoperative value.

Abbreviations: $L$, left; $R$, right.

using topical medication. ${ }^{20,21}$ It has been reported that tear composition differs in stimulated tears ${ }^{6,7}$ and that lactoferrin and lipocalin-1 concentrations are decreased in dry eye conditions. ${ }^{9}{ }^{18}$ However, extreme low concentrations as observed in our patient have not been reported.

The high concentration of tear albumin in our patient is another interesting finding. Albumin, a major protein in the serum, is found in low concentrations in tears, ${ }^{6,7}$ and reports have shown varied tear albumin concentrations, even in normal subjects, and increased tear albumin levels in patients with dry eye. ${ }^{12,15}$ The tear albumin concentration in our patient was more than double of that in controls and further increased with punctal occlusion, supporting the diagnosis of congenital alacrima and shedding light on the efficacy of punctal occlusion.

In our patient, punctal occlusion resulted in improved tear retention and ocular surface findings. The source of tear fluid is typically presumed to be the main or accessory lacrimal glands; however, tear protein composition in our patient suggests that the source may, at least partly, be the conjunctival epithelium. It has been assumed that conjunctival water secretion occurs via a chloride channel. ${ }^{22}$ Cerretani and Radke have estimated that to compensate for the high osmotic pressure of tear fluid, conjunctival cells produce water and account for $\sim 10 \%$ of the tear fluid in normal subjects and $25 \%-50 \%$ in patient with dry eye. ${ }^{23}$ Punctal plug insertion and punctal occlusion are widely used in the treatment of refractory tear-deficient dry eye. The increased tear volume in such cases is partially due to increased conjunctival water secretion. As albumin concentrations have been reported to be high in patients with dry eye, we believe that this hypothesis is worth considering in the therapeutic mechanism of punctal occlusion.

A possible limitation of our current study is that the age of control subjects does not match the patient. However, according to the report of Esmaeelpour and associates, ${ }^{24}$ tear protein compositions of infants (postnatal age: $7.8 \pm 6.1$ weeks) do not differ much from adults except for a decrease in IgA concentration. The patient in our study is 13 years old, and we believe that the distinct tear protein profile of our patient cannot be explained by the age. Another limitation is that the finding of this current study is based on a single patient. Although congenital alacrima is an extremely rare disease, more patients with alacrima should be examined in the future to confirm the results of our study.

\section{Conclusion}

We treated a patient with presumed congenital alacrima with no family history or systemic findings. Tear protein analysis of the patient differed from that of controls and revealed minimal concentrations of the major tear proteins. Even though our patient was severely tear deficient, punctal occlusion was found to be effective, suggesting that tear protein analysis may be useful in assessing the efficacy and mechanism of this procedure.

\section{Acknowledgment}

This study was supported by a grant (\#23592600) from the Ministry of Education, Culture, Sports, Science, and Technology, Japan.

\section{Author contributions}

All authors contributed to data analysis, drafting and revising the article, gave final approval of the version to be published, and agree to be accountable for all aspects of the work.

\section{Disclosure}

The authors report no conflicts of interest in this work.

\section{References}

1. Mondino BJ, Brown SI. Hereditary congenital alacrima. Arch Ophthalmol. 1976;94(9):1478-1480. 
2. Hegab SM, Sheriff SM, El-Aasar ES, Lashin EA, Phillips CI. Congenital alacrima without associated manifestations (AD). An affected father and son. Ophthalmic Paediatr Genet. 1991;12(4):161-163.

3. Hegab SM, Al-Mutawa SA. Congenital hereditary autosomal recessive alacrima. Ophthalmic Genet. 1996;17(1):35-38.

4. Ikeda M, Hirano M, Shinoda K, et al. Triple a syndrome in Japan. Muscle Nerve. 2013;48(3):381-386.

5. Nakamura K, Yoshida K, Yoshinaga T, et al. Adult or late-onset triple a syndrome: case report and literature review. J Neurol Sci. 2010; 297(1-2):85-88.

6. Fullard RJ, Tucker DL. Changes in human tear protein levels with progressively increasing stimulus. Invest Ophthalmol Vis Sci. 1991;32(8): 2290-2301.

7. Fullard RJ, Snyder C. Protein levels in nonstimulated and stimulated tears of normal human subjects. Invest Ophthalmol Vis Sci. 1990;31(6):1119-1126.

8. Runström G, Mann A, Tighe B. The fall and rise of tear albumin levels: a multifactorial phenomenon. Ocul Surf. 2013;11(3):165-180.

9. Versura P, Bavelloni A, Grillini M, Fresina M, Campos EC. Diagnostic performance of a tear protein panel in early dry eye. Mol Vis. 2013; 19:1247-1257.

10. Perumal N, Funke S, Pfeiffer N, Grus FH. Proteomics analysis of human tears from aqueous-deficient and evaporative dry eye patients. Sci Rep. 2016;6(1):29629.

11. Willcox MDP, Argüeso P, Georgiev GA, et al. TFOS DEWS II tear film report. Ocul Surf. 2017;15(3):366-403.

12. Azkargorta M, Soria J, Acera A, Iloro I, Elortza F. Human tear proteomics and peptidomics in ophthalmology: toward the translation of proteomic biomarkers into clinical practice. J Proteomics. 2017; 150:359-367.

13. Dartt DA. Regulation of mucin and fluid secretion by conjunctival epithelial cells. Prog Retin Eye Res. 2002;21(6):555-576.
14. Gaffney EA, Tiffany JM, Yokoi N, Bron AJ. A mass and solute balance model for tear volume and osmolarity in the normal and the dry eye. Prog Retin Eye Res. 2010;29(1):59-78.

15. Cerretani CF, Radke CJ. Tear dynamics in healthy and dry eyes. Curr Eye Res. 2014;39(6):580-595

16. Shimazaki J, Tsubota K, Kinoshita S. Definition and diagnosis of dry eye. Atarashii Ganka. 2007;4:181-184.

17. Kawashima M, Yamada M, Suwaki K, et al. A clinic-based survey of clinical characteristics and practice pattern of dry eye in Japan. $A d v$ Ther. 2017;34(3):732-743.

18. Yamada M, Mochizuki H, Kawai M, Tsubota K, Bryce TJ. Decreased tear lipocalin concentration in patients with meibomian gland dysfunction. Br J Ophthalmol. 2005;89(7):803-805.

19. Shigeyasu C, Hirano S, Akune Y, Mochizuki H, Yamada M. Evaluation of the frequency of ophthalmic solution application: washout effects of topical saline application on tear components. Curr Eye Res. 2013;38(7):722-728.

20. Tong L, Zhou L, Beuerman R, Simonyi S, Hollander DA, Stern ME. Effects of punctal occlusion on global tear proteins in patients with dry eye. Ocul Surf. 2017;15(4):736-741.

21. Sack RA, Tan KO, Tan A. Diurnal tear cycle: evidence for a nocturnal inflammatory constitutive tear fluid. Invest Ophthalmol Vis Sci. 1992; 33(3):626-640.

22. Versura P, Bavelloni A, Blalock W, Fresina M, Campos EC. A rapid standardized quantitative microfluidic system approach for evaluating human tear proteins. Mol Vis. 2012;18:2526-2537.

23. Zhu H, Chauhan A. Tear dynamics model. Curr Eye Res. 2007;32(3): 177-197.

24. Esmaeelpour M, Watts PO, Boulton ME, Cai J, Murphy PJ. Tear film volume and protein analysis in full-term newborn infants. Cornea. 2011;30(4):400-404.
Clinical Ophthalmology

\section{Publish your work in this journal}

Clinical Ophthalmology is an international, peer-reviewed journa covering all subspecialties within ophthalmology. Key topics include: Optometry; Visual science; Pharmacology and drug therapy in eye diseases; Basic Sciences; Primary and Secondary eye care; Patient Safety and Quality of Care Improvements. This journal is indexed on

Submit your manuscript here: http://www.dovepress.com/clinical-ophthalmology-journal

\section{Dovepress}

PubMed Central and CAS, and is the official journal of The Society of Clinical Ophthalmology (SCO). The manuscript management system is completely online and includes a very quick and fair peer-review system, which is all easy to use. Visit http://www.dovepress.com/ testimonials.php to read real quotes from published authors. 